\title{
To feel like an outsider: focus group discussions regarding the influence on sexuality caused by breast cancer treatment
}

\author{
Kicki Klaeson, K Sandell and Carina Berterö
}

\section{Linköping University Post Print}

N.B.: When citing this work, cite the original article.

This is the authors' version of the following article:

Kicki Klaeson, K Sandell and Carina Berterö, To feel like an outsider: focus group discussions regarding the influence on sexuality caused by breast cancer treatment, 2011, European Journal of Cancer Care, (20), 6, 728-737.

which has been published in final form at:

http://dx.doi.org/10.1111/j.1365-2354.2011.01239.x

Copyright: Blackwell Publishing http://www.blackwellpublishing.com/

Postprint available at: Linköping University Electronic Press http://urn.kb.se/resolve?urn=urn:nbn:se:liu:diva-71684 


\section{To Feel Like an Outsider - Focus group discussions regarding the influence on sexuality caused by breast cancer treatment}

Kicki Klaeson RN, MPH and PhD-student. Department of Medical and Health Sciences, Faculty of Health Sciences, Linköping University, and Surgical Clinic, Oncology Department Lidköping Hospital Sweden.

Kerstin Sandell PhD, Associate Professor, Department for Gender Studies, Lund University, Sweden.

Carina M Berterö, RN, RNT, BSc, MScN, PhD, Associate Professor

Division of Nursing Science, Department of Medical and Health Sciences, Faculty of Health Sciences, Linköping University, Sweden.

\section{Acknowledgements}

The authors are grateful to all those women who participated and shared their experiences with us. We are also grateful to the Skaraborg Institute for Research and Development, Research and Development Unit at Skaraborg's Hospital and Faculty of Health Sciences, Linköping University, for financial support. We are thankful to Geoff Dykes for revising the manuscript.

Address for reprints: Kicki Klaeson, Surgical Clinic, Oncology Department Lidköping Hospital, Sweden. Fax: (046) 510-85596; E-mail: kicki.klaeson@ telia.com 


\section{ABSTRACT}

The aftermath of breast cancer treatment, especially the sexual side effects, appear to be a neglected issue in Western society. The purpose of this study was to explore how middle-aged women treated for breast cancer experienced their identity connected to the community norms an values in the society as a whole. Three focus group interviews were conducted, with a total of 12 women. The discussions were analysed using qualitative content analysis. The main theme to feel like an outsider symbolises the women's situation after breast csancer treatment. Hey experienced their body in a wholly new unfamiliar way, ehich affected their sexuality in a deep and profound way. This feeling affected their female roles and overshadowed earlier experiences in life. All their female roles were suddenly vague and this was expressed in various ways across each of the four subthemes: to feel different, the unruly body, eroticism is not what it used to be and re-evaluating. From a nursing perspective, there appears to be a definite challenge to identify the women's own unique sexual needs in the rehabilitation transition and to use the skills from all team professionals to improve sexual health in this context.

\section{Keywords Breast cancer; Femininity; Premenopausal women; Qualitative Content}

\section{Analysis; Sexuality}




\section{INTRODUCTION}

Today breast cancer is the most common cancer among women worldwide, and the number of cases are increasing (The World Health Organisation 2008; The Swedish Cancer Society 2009). Breast cancer treatment regimens have become more aggressive and many women must undergo surgery, radiation, and/or chemotherapy as well as approximately five years of hormone therapy (The World Health Organisation 2008; The Swedish Cancer Society 2009). Consequently today's breast cancer survivors, who live in developed countries, have a relatively good prognosis unlike those who have other forms of cancer. The highest survival rates in Europe are in the north area and in Sweden it is as high as $87.8 \%$ (The World Health Organisation 2008; The Swedish Cancer Society 2009). The treatment regimens are similar in most European countries and only small differences occur regionally or locally (The World Health Organisation 2008). Treatment for recurrent disease can lead to a longer life, but the need for chemotherapy and/or hormone therapy for several years can have an impact on quality of life (The National Academy of Sciences 2007; The World Health Organisation 2008; The Swedish Cancer Society 2009).

Today the majority of women with early stage of breast cancer are offered breast conserving surgery (BCS), and while it has been shown that this less mutilating surgery has resulted in a more positive body image it has not had the direct positive impact on sexual functioning that had been hypothesised (Rowland et al., 2000, Rogers and Kristjanson, 2002). What has been found is that the chemotherapy and hormonal therapy regimens used as adjuvant treatment for breast cancer have a greater impact on psychosexual functioning than the type of surgical procedure used for primary treatment (Mortimer et al., 1999, Rogers and Kristjanson, 2002). Earlier research in this area suggests that women who have felt that they had some control over their treatment options before having surgery and could decide themselves if either lumpectomy or mastectomy should be carried out, have later been more satisfied with their sexuality and body image (Rowland et al., 2000). Another finding is that women who think positively about the sexual aspects of their identity before receiving their diagnosis often remain more satisfied with their sexuality after treatment (Andersen and Cyranowski, 1994).

Female sexual function is highly complex, and for women who are pre-menopausal when they are diagnosed with breast cancer, the chemo- and/or hormone-therapy can lead to a permanent menopause which then impacts on their fertility, sexual desire, arousal and possibility 
for orgasm (Young-McCaughan, 1996, Ganz et al., 2003). Women younger than 50 years who are diagnosed with breast cancer are more vulnerable to sexual problems caused by chemotherapy and hormonal therapies than are older women with the same diagnosis (Knobf, 1998, Burwell et al., 2006). The effects on body-image and the fear of recurrence also contribute to their vulnerability (Burwell et al., 2006). The experience of hot flushes and artificial treatment-induced menopause are further issues which affect women's sexuality in a wider perspective (Knobf, 1998, Burwell et al., 2006, Fenlon and Rogers, 2007, Fenlon et al., 2009). Women with treatment induced menopause can display a higher frequency of mood swings, a higher incidence of hot flushes, sleep disturbance, vaginal dryness and an increased probability of depression than women who have undergone a natural menopause (Knobf, 1998, Burwell et al., 2006, Fenlon and Rogers, 2007, Fenlon et al., 2009).

The literature suggests that some of the women who experienced a natural menopause report a declining sexual interest and increased likelihood of pain during intercourse caused by vaginal dryness (Murkies, 1996, Addis et al., 2006). Generally, studies from Europe, USA and Australia confirm that in a healthy population it is more likely that women are more dissatisfied with their sexual quality compared to males (Murkies, 1996, Swedish National Institute of Public Health, 1996, Addis et al., 2006). Qualitative data suggest that woman's perceptions, different gender roles and feelings of femininity are most important for healthy sexuality (Wilmoth Chamerlain, 2001). Sexual health is, according to the World Health Organization (WHO) the ongoing process towards physical, psychic and socio-cultural wellbeing connected with sexuality (WHO and Sexology, 2000). Sheerin and McKenna (2000) define the concept of sexuality as being essential to nursing care. They suggest that a person's definition of sexuality is developed as a result of four interrelated processes: 1) sexual identity as perceived by themselves at any given time: 2) communication of beliefs, impulses and qualities associated with this identity: 3) reciprocation, reception and understanding of all outcomes connected to sexual identity: 4) gratification of self or other(s) (Sherin \& McKenna 2000). This implies the need for health care professionals to meet and confirm the woman and her partner in a new way than was the practice earlier (Wilmoth Chamerlain, 2001, Klaeson and Berterö, 2008).

Hence the purpose of this study was to explore how middle-aged women, who were still menstruating when, diagnosed with a breast cancer diagnosis, experienced their sexuality through the changes brought forth by breast cancer and its treatment. 
How do they express feelings connected to femaleness and bodily experiences?

What is the gratification in sexual life and closeness with partners and friends?

\section{METHODS}

Three focus groups, aiming to capture the underlying meaning of sexuality, were used for this qualitative study. Initially two focus group interviews was planned since this was a follow up study where women already had been interviewed individually in the same context (Klaeson \& Berterö, 2008). When the analysing of the two first focus group interviews had progressed the researchers decided to make one more interview to ensure trustworthiness in the findings. The analytic process is systematic and based on understanding in addition to the substance in the three group discussions. The study was performed in the context of support group members.

\section{Sample}

Informants were recruited through chair persons of two different support groups for women with breast cancer in the south of Sweden, and were initially contacted by a personal letter. The criterion for participation in the study was that the members of the support groups were women who were younger than 50 years at the time of their diagnosis and still menstruating. The time period of diagnosis was set to at least six months. The personal letter sent to potential informants requested their participation in a focus group interview study and gave information about the purpose of the study. The 12 women who showed their interest by signing the informed consent form were contacted by the first author (KK). All except one were Caucasian and native Swedish speakers, but all focus group discussions were conducted in Swedish. The study was approved by the Regional Ethics Committee in Gothenburg, Sweden. In accordance with the Helsinki declaration the women were insured anonymity, confidentiality and voluntarily throughout the process (MRC 2000). If they needed to talk to someone after the interview, about some topic which had been discussed, they were offered to call the psycho-social department nearby.

The women's ages varied between 39 and 54 years, with a median of 47 years. There were variations of lived experiences in each focus group. Eight of the informants were disease-free and four were relapsed. Four out of twelve women were single and the remaining women were cohabitating or married. Seven of them lived together with children under eighteen years of age and one was childless. The time lapse since diagnosis varied from one year to ten years with a 
median of three years across all the focus groups. The relapsed women had been relapsed for a median of four and a half year. Characteristics of the focus group informants are illustrated in table 1 .

Table 1. Characteristics of the focus groups participants'

\begin{tabular}{|c|c|c|c|}
\hline $\mathrm{n}=12$ & $\begin{array}{l}\text { Focus group } 1 \\
\mathrm{n}=4\end{array}$ & $\begin{array}{l}\text { Focus group } 2 \\
n=4\end{array}$ & $\begin{array}{l}\text { Focus group } 3 \\
n=4\end{array}$ \\
\hline Age range & $39-45$ years & $46-53$ years & $46-54$ years \\
\hline Time for menopause & $30-43$ years & $* 45-46$ years & $39-48$ years \\
\hline \multicolumn{4}{|l|}{ Type of surgery } \\
\hline Mastectomy & $\mathrm{n}=3$ & $\mathrm{n}=3$ & $\mathrm{n}=3$ \\
\hline Partial mastectomy & $\mathrm{n}=1$ & $\mathrm{n}=1$ & $\mathrm{n}=1$ \\
\hline Breast reconstruction & $\mathrm{n}=0$ & $\mathrm{n}=1$ & $\mathrm{n}=1$ \\
\hline
\end{tabular}

\section{Type of Therapy}

$\begin{array}{llll}\text { Chemotherapy } & \mathrm{n}=4 & \mathrm{n}=2 & \mathrm{n}=2 \\ \text { Radiation } & \mathrm{n}=2 & \mathrm{n}=2 & \mathrm{n}=4 \\ \text { Tamoxifen or Arimidex } & \mathrm{n}=4 & \mathrm{n}=3 & \mathrm{n}=4 \\ \text { GnRH analouge } & \mathrm{n}=1 & \mathrm{n}=1 & \mathrm{n}=1 \\ \text { Herceptin } & \mathrm{n}=0 & \mathrm{n}=0 & \mathrm{n}=1\end{array}$

At time for the focus group discussions all women except one were treated with hormones, who was in supply of Herceptin

*One woman were still menstruating at time for the focus group interview

\section{Procedures}

The focus group sessions were carried out at the same place as the support group (s) had their meetings, with the exception of one group where the focus group meetings were conducted at the home of one of the support group members. Before the session started, the moderator $(\mathrm{KK})$ explained the purpose and the topic for the session. First there was some small talk in order to bring the informants together and to help them to get to know each other. The group dynamics 
differed in each of the three groups. In every group there were some women who already knew each other, and in focus group two there was a pair of close friends. During the session the women were encouraged to talk to one another, to ask questions, exchange anecdotes and comment on each other's experiences. The moderator steered the focus of the group discussions and ensured that the dialog occurred among the group members; rather than between them and the moderator. The moderator of the focus groups was a trained oncology nurse familiar with and sensitive to the topics being discussed. The sessions lasted 110-130 minutes and were audiotaped.

\section{Data Analysis}

The tapes were transcribed verbatim. The analysis was conducted in Swedish. Qualitative content analysis was used, inspired of Graneheim and Lundman 2004 and Hsie and Shannon (2005), for the analysis aiming for interpretation of the underlying meaning of the text. In contrast to manifest content analysis which is aiming for a systematic description, the latent analysis includes interpretations. Therefore the latent analysis is more profound and more abstracted (Graneheim and Lundman, 2004; Hsieh \& Shannon 2005). The analysis was conducted in four steps.

In step 1) the text was read through several times to obtain a sense of the whole. In step 2) the focus groups transcript were analysed line by line, and meaning unit were identified. In view of the context, the meaning units were condensed into a depiction close to the text which is the manifest phase. Where it was possible an interpretation of the underlying meaning was labelled the latent phase. The analyst went back and forth through the text, wrote notes in the margins to help to discover patterns in order to understand the underlying meanings. In step 3) the condensed meaning units were abstracted and labelled as a sub-theme. We used sub-themes instead of sub-categories since the texts in sub-themes and themes overlap each other by contrast to sub-categories and categories. During steps 2 and 3 the first author discussed the material with the other authors, reviewed the illustrated sketches and referred back to the original text several times. In step 4) all the text masses were compared with each other and the text was abstracted to a higher level. The sub-themes were then prearranged into a framework that depicted aspects of the process in sexuality among the sample of informants. One theme finally emerged from this process. (Table2). After completed analysis the phenomenon and the findings were translated to 
Table 2. Analysis of the text; giving some examples step $2-4$

\begin{tabular}{|c|c|c|c|c|}
\hline Meaning Unit & $\begin{array}{l}\text { Condensed meaning } \\
\text { unit ( Description } \\
\text { close to the text) }\end{array}$ & $\begin{array}{c}\text { Condensed meaning } \\
\text { unit (Interpretation of } \\
\text { the underlying } \\
\text { meaning) }\end{array}$ & Sub-theme & Themeaning \\
\hline $\begin{array}{l}\text { 1a. No, it is that I want - I want to be like all the others, a little. } \\
\text { It isn't me any longer, this woman with only one breast. } \\
\text { She isn't me, I don't feel like that. }\end{array}$ & $\begin{array}{l}\text { This informant is } \\
\text { longing to look like } \\
\text { healthy women. She } \\
\text { doesn't feel like a } \\
\text { woman with only one } \\
\text { breast. }\end{array}$ & $\begin{array}{l}\text { A feeling of being } \\
\text { different from other } \\
\text { women and a longing to } \\
\text { be "normal" again. }\end{array}$ & Feeling different & \multirow{4}{*}{$\begin{array}{l}\text { To feel like an } \\
\text { outsider }\end{array}$} \\
\hline $\begin{array}{l}\text { 1a. I have thought about the fact that when talking about breast } \\
\text { cancer it is always the breast, its loss and the eventual loss of hair } \\
\text { from the treatment but I feel that it is not these things that have } \\
\text { changed me as a woman rather it is the flushes. } \\
\text { 1b. Yes I really do agree with you. } \\
\text { la. It's the hormones. } \\
\text { 1b. That's right. One is not used to seeing this, now I begin to } \\
\text { understand and notice that my body has begun to change around } \\
\text { the hips and it isn't that I want to be thin but I look bloated. } \\
\text { 1c. Me too. I have gone up } 10 \text { kilos in weight. }\end{array}$ & $\begin{array}{l}\text { Participants are } \\
\text { discussing bodily } \\
\text { changes since they had } \\
\text { finished menstruating. } \\
\text { They do not know why, } \\
\text { but someone believes } \\
\text { that it is the hormones } \\
\text { that are causing the } \\
\text { troubles. }\end{array}$ & $\begin{array}{l}\text { Hormones cause bodily } \\
\text { changes. One feels } \\
\text { older, more bloated and } \\
\text { one has flushes. }\end{array}$ & $\begin{array}{l}\text { The Unruly } \\
\text { Body }\end{array}$ & \\
\hline $\begin{array}{l}\text { 3a. I don't feel it any more... a little like you said before... a little } \\
\text { as if it doesn't matter if a man looks at me... Sometimes a } \\
\text { woman can feel as... oh, he looks at me - but that feeling is } \\
\text { dead... and it feels as if... I know that Charlie (her husband) } \\
\text { loves me } 500 \text { million per cent and he is turned on by me and all } \\
\text { that... } \\
\text { 3c. I recognize all that. } \\
\text { 3a. I would like to have the lust... but it's gone... (Everybody is } \\
\text { talking). }\end{array}$ & $\begin{array}{l}\text { Two informants have } \\
\text { noticed changes in the } \\
\text { interaction with men. } \\
\text { The lust is gone and she } \\
\text { wants it back. }\end{array}$ & $\begin{array}{l}\text { The sexual interaction } \\
\text { has changed. The lust is } \\
\text { gone, and they miss it. }\end{array}$ & $\begin{array}{l}\text { Eroticisms is not } \\
\text { what it used to } \\
\text { be }\end{array}$ & \\
\hline $\begin{array}{l}\text { 2a. Well, but I also think that we revalue our friends a little or so } \\
\text { our called friends. We take away some people we know - I don't } \\
\text { fell well about you. We think: I want to feel well, I want to feel as } \\
\text { well as I only can. And then we'll be a little bit tougher, I think. }\end{array}$ & $\begin{array}{l}\text { To be tougher and } \\
\text { revaluate friends, to } \\
\text { take away some the } \\
\text { chances to feel well } \\
\text { increases. }\end{array}$ & $\begin{array}{l}\text { Communication and } \\
\text { interaction with other } \\
\text { people have changed. } \\
\text { The informants are } \\
\text { more selective than } \\
\text { before. }\end{array}$ & Re-evaluating & \\
\hline
\end{tabular}


English and a native born Englishman working with language revision had discussions with the researchers aiming for finding and using the correct words presenting the nuances in the findings.

\section{FINDINGS}

Conducting qualitative content analysis identified four sub-themes and one final theme. The subthemes were; to feel different, the unruly body, eroticism is not what it used to be and reevaluating and are all related to the main theme; to feel like an outsider.

\section{To feel different}

The women appeared to have difficulty in verbalising their positive feelings connected to the female body. Instead they expressed an overwhelming feeling of not recognising themselves and not knowing with whom to identify themselves. The younger women seemed to be more vulnerable and some of them identified themselves with their mothers. The women struggled to adjust to their new "body shell" with its changed physical appearance as well as to cope with existential thoughts emanating from their cancer disease. The women felt unfeminine even if they did not expressed explicitly that the loss of a breast or even a part of a breast constituted the reason for this. Instead the implication was that they felt different because of changes in their body image - their changed body signalled ageing and illness.

"I have considered when you are talking about breast cancer, it's always the breast, the loss of the breast. // But I feel that this isn't what has changed me as a woman, instead it's everything which comes afterwards. Yes this thing with hot flashes.” (Informant focus group 1)

In response to these signals the majority of the women put a great deal of energy into showing the outside world that they were healthy and normal by taking extra care with their clothing and makeup.

“When I began to use a wig, of course I couldn't show that I was ill, it mustn't been seen that I have a cancer illness. Nobody was allowed to see that." (Informant focus group 2) 
In the first focus group, where the informants were younger, it was more noticeable than in the other groups that the women felt different because of their rapid body changes. They did not know to which female group they should identify themselves; should it be with the older population with the same menopausal symptoms as they had, or was it with the younger population of the same age but without the same bodily experiences? The women felt that they did not fit into any particular context.

"And suddenly I feel that I am at the same age as my mother. // Well, we have the same problems (laughter) to talk about, 'hot flashes' and sweating and I feel that I have become unbelievably like her in my manner." (Informant focus group 1)

Three quarters of the women who had gone through a mastectomy were uncomfortable in situations that arose in those places where nakedness occurs in the presence of unknown people e.g. public baths. They expressed that they felt a sense of guilt as they felt that their mutilated bodies made people feel embarrassed. Mostly, it was their concern for other people rather than for themselves that made them hide their bodies. These women felt their situation to be very private and it was hard for them to express their thoughts in words and some of them felt that these kinds of situations were simply too much for them. It was obvious that they longed for what was for them, a normal life.

"But before I got my breast rebuilt, I had one left at first and then I thought it was terrible. I was so embarrassed... or what I thought - just phew. // I should make sure that everybody was away and I got a towel hanging over and showered so that nobody could see me. And I tip-toed and I tip-toed - I thought it was embarrassing, I know that I thought so." (Informant focus group 2)

\section{The Unruly Body}

The changes, specifically brought by the treatments, had a huge impact on the women's bodies. This was expressed by the women as their body being unruly. They experienced their body as 
unpredictable and as their body had let them down, they were unable to continue with their normal life. The new unfamiliar body appearance with scars, breast and hair loss made the women feel uncomfortable in their daily lives. The change in their face, once their eyelashes and eyebrows were lost due to chemotherapy, was most troubling as such losses cannot be hidden like head hair loss can be by the use of wigs and scarves.

"But the eyebrows and the eyelashes!"

"It was tremendously heavy. I thought that it was more difficult than when the hair disappeared. If you don't have hair you can tie a shawl, or use a wig. // But the eyebrows - you couldn't do anything. You had to paint... I was lucky to be able to go this course so I could learn. " (Two informants focus group 2)

All the efforts to hide their body changes and to act as if everything was as normal as usual were most tiresome plus the fact that treatment induced fatigue was common, all this affected the women's well being and made them feel their body had let them down. The women expressed feeling old as their body became stiffer; they felt clumsier and had difficulty in dealing with the symptoms connected to the menopause caused mostly by chemotherapy. They had difficulty to accept that these symptoms as being normal. Older women and those who had lived with their disease for several years had accepted the changes and observed with some relief that their friends had also finally reached the menopause and that they were no longer alone in this situation. Vasomotor symptoms made the women feel less feminine due to the fact that they did not feel fresh when they were dripping with sweat and their face was flushed. At the same time they had difficulties to concentrate within this situation, which made them feel unnatural when out among people.

"So it wasn't Mira. It was exactly as if I was in another body in a way... or." (Informant focus group 1) 
For the majority of the women it was important to retain their femininity as it was before. Such things as brassieres, style of clothing and other female accessories were expressed as being important because these attributes gave them self-confidence and made them feel healthy and normal. The insight that they no longer could purchase standard or sometimes sexy clothes in ordinary shops, just as everyone else, was a further disappointment and fortified their feeling of being an outsider. Furthermore, it was frustrating when weight gain, sometimes caused by the treatment, forced them to buy clothes of a larger size than earlier. Sometimes they had to change their whole style because of this.

\section{Eroticism is not what it used to be}

The women who lived with a partner were all sexually active and despite experiencing many alterations to their sexuality, the woman had not reflected on these changes until the focus group discussions made it visible to them. Sexual desire was expressed in the way that the women thought of themselves as a woman attracted to males and was the core meaning of the word "sexuality". When these women talked about their own desire they described it as a "tingle". This was still possible to bring about, but it demanded time and mental preparation but sometimes the excitement just did not happen. Some women were aware of their lack of desire and were able to talk with their partner about it.

"Well for my part... I suppose it was less and less and less lust from my side. // And then Alan said one evening; why do I always have to seduce you? Why is it up to me to turn you on? Probably it is a thing you must accept, that if you get turned on, you must turn me on. I don't get turned on by myself." (Informant focus group 3)

The informants indicated that their feelings of sexual attraction to men just didn't happen like it used to and that this had a negative effect on how they viewed their womanliness. When they interacted with other men than their partner, such as work colleagues etc., they didn't feel any of the dynamics which they were used to and they missed this. During intercourse with their partners they were not relaxed and they did not feel that they could totally immerse themselves like they used to when making love. If they tried to use a pornographic movie in order to increase their desire, the result was mostly that they just felt disgusted. For them, this passive, 
uninvolved role was difficult to cope with. For the informants this loss of desire was expressed as being a huge loss and they longed to be the woman they once were.

"And then the rest comes too and it is really, very bad. I miss the sex, I miss the lust, I miss my womanliness.” (Informant focus group 3)

The majority of the informants seemed to live in harmonic relationship with their partner and expressed that they felt loved and appreciated. They often felt that they were in phase as a couple where instead of having intercourse they just laid closely entwined with each other. This increased their sense of intimacy and that gave some balance into their love-life despite the changes brought about by their illness and treatment. This made them feel secure and perhaps more loved, albeit not in an erotic way. These feelings were most beneficial for the quality of their intimate relation with their partners.

"I have felt that we have lived life as retired people now (laugh). We are lying, holding hands, hugging and yes, yes it has been improved. But I have felt that we have been very much in harmony with each other. Felt that... I have never felt that I have had to turn him down." (Informant focus group 1)

Only a few of the women gave an impression of insecurity through not being able to live up to their "duty" in heterosexual relations. They were afraid of being left alone and they did not dare to break up their relation because of the feeling that they were no longer attractive and some women even argued that the cancer disease was the cause of their damaged relationship.

"But I felt that if it would go to hell with my husband - who else would want me? Nobody wants someone like me.” (Informant focus group 2)

\section{Re-evaluating}


The discussions differed within the three focus groups. It was brought forth that those women with recurrent disease, and those who had lived with the aftermath of the disease for some years, had changed their attitude towards life. Also the meaning of life had become a central aspect for them. As a consequence they choose only the friends who made them feel comfortable. At the same time they could confirm and appreciate other people's engagement in them in a completely new way. They could also, more consciously, make time for their own interests, for example exercising, or just socialising. In the group discussions it was noticeable that the informants felt that their lives had been overthrown when their femininity was transformed. All their ways of perceiving were affected and the emotions connected to those experiences were, from the beginning, inconceivable for them. Over time they became more familiar with these new emotions and a redefinition of "the self" emerged. This redefinition of "the self" was connected to their awareness of mortality and living with an uncertain future which had an everyday impact on their interaction and communication with others. Some informants had learned to respect themselves in a different way than before and this feeling made them more relaxed in all of the female roles in their life. It made their close relations so much deeper and richer and finally their life-perspective changed.

"People who really know me, they know or they feel that it is something I want and they understand me. But it isn't necessary that everybody will understand me, I don't understand myself in the same way as I did before." (Informant focus group 3)

To be confirmed as a woman was essential for the women's well-being and feelings of femininity. Closeness to their children, close friends and/ or their partner and the other women in the support groups offered them confirmation without the need for words. These intimate relations compensated to some degree those losses connected to their decreased interest towards men, desire and their own lack of attractiveness.

\section{To feel like an outsider}

The findings from the focus group discussions manifest that being diagnosed with breast cancer, and the treatment which follows, implicate changes in the body. The women felt intuitively that they "were their bodies", which also affected their minds with unfamiliar feelings and thoughts. 
The most prominent feeling was that they felt like an outsider. To feel like an outsider was expressed in various ways; e.g. not being able to cope and accept their new situation and also to feel different - you are not a fully satisfactory woman, wife, mistress, mother, workmate or friend anymore. The quote below symbolise what the women felt in the context to other healthy women.

"No, it is that I want - I want to be like all the others, a little. It isn't me any longer this woman with only one breast. She isn't me, I don't feel like that. As I said, I feel that I have left that a little bit behind, now I am like all the others and then I want to look as all the others." (Informant focus group 1)

The feeling of being an outsider could later on also originate from personal maturity and reevaluation of "the self". The women changed their focus from material interests towards focusing and concentrating on themselves. The theme to feel like an outsider includes suffering but also in the long run an opportunity for personal growth. The sexual dimensions during this transition period are often fluctuating and individual. The intimacy they shared in the support groups strengthened their ability in the society to cope as an outsider and seemed to be most beneficial and essential for the women's sexual health and womanhood.

\section{DISCUSSION}

The findings from these three focus group discussions confirm that the process of alteration after a breast cancer diagnosis and treatment is complex as a result of its multidimensional construction and the different norms and values within society. The theme; to feel like an outsider, includes both great suffering and personal maturity. The suffering is related to body changes and not feeling familiar with those emotions and thoughts which bring about changes in relationships with family members and friends, expectations related to the female role function within society. Personal maturity is the result of an adjustment to a life threatening disorder. It is important that professionals understand that the transition towards accepting a new and altered sexual self is in no way linear. As in earlier studies by Wilmoth (2001), three adjustment phases are common; taking in, taking hold and taking on. Taking in; concerns adjusting to the life threatening disease diagnosis and the subsequent bodily changes, taking hold; concerns coping with all the losses and life changes that are the result of the disease and finally taking on; 
concerns acceptance, for which personal maturity is a natural consequence (Wilmoth Chamerlain, 2001). These phases were initially discovered by Rubin in the nineteen-sixties in the context of mothers with newborns and have many similarities with the transition phases described by Schumacher and Meleis (1994) and Wilmoth (2001). In these studies, as well as in ours no specific time period for this adjustment process was evident. However the meaningmaking component of taking hold could not begin until the taking in of the diagnosis from the disease had been completed. Our study indicates that the taking in process is probably more complex and difficult for the women to handle than earlier studies have shown. To feel like an outsider was also an over bridge theme in a qualitative study with 12 women suffering from recurrent gynaecological cancer. The structure of the study aiming to capture the lived experience in a similar female context strengthened our findings and lightened the women's vulnerability diagnosed with a cancer disease (Ekwall et al. 2007).

Contrary to other studies within the context of breast cancer survivors, the informants in our study did not explicitly express that the loss of a breast or even a part of a breast constituted a loss of femininity to themselves or affected their relation with their partners (Kaplan, 1992, Rowland et al., 2000). Instead the implication was that they felt like an outsider in that the changed body signalled illness. It seemed as if the women themselves took responsibility for not letting those around them feel embarrassed by their illness. The bodily changes that were caused by the treatment and their identification with their mothers initiated an ageing process. On the other hand this ageing process seemed to be more important for the participant's feelings of femininity than the breast loss. In modern western societies physical appearance for women is shaped by the "social norm" to look young and slim throughout the middle-ages (Blood, 2005). This norm obstructs people's ability to cope with ageing and illness and in the context of middleaged women with breast cancer this is made clearly visible.

In our study sex was viewed as a basic mutual need between couples and a normal way to live. The loss of femininity, lust and satisfactory intercourse therefore became distressing which in turn affected the women's already vulnerable transition towards redefining their sexuality. To have support, love and confirmation was therefore essential and the effort to experience this was the direct consequence of the informants coping strategies. In spite of this the level of gratification from intimate relations seemed to be high, and even though the erotic part was dampened the intimate relations became stronger. It was also established that having their own 
children could in some way validate the women's confirmation of their sexuality and womanhood; women with children seemed to be less frustrated in their female role. The sisterhood created, in this context, by the support group members probably played a determining factor for the women's development and regeneration of her sexuality. From a feministic view women are often seen as nurturers and are expected to prioritise the needs of others above their own (Sulik, 2007). The women in this study may be considered as having had to break gender norms and to give themselves permission to think about their own needs.

Personal maturity seemed to be most beneficial for the close relationships and coping resources of the informants and the findings confirm earlier studies taken from a similar context that personal maturity often is a result when people are threatened by a life threatening disorder (Berterö and Wilmoth, 2007). In a meta-synthesis of 30 qualitative research reports based on the perspective of breast cancer suffering women, four aspects relating to the person being affected by the diagnosis were found (Berterö and Wilmoth, 2007). These aspects; awareness of mortality, living with an uncertain future, attachment validation and redefinition of "the self", were also seen in our study (Berterö and Wilmoth, 2007). The complexity in adapting to a new "self" at the same time as one is struggling with an unfamiliar body, influenced the informants self-respect not only by the women's view of themselves but also by the reaction from their partner or a close friend, which highlights their need for personal confirmation. To re-evaluate friendships which did not fulfil the women's own requirements for self-realisation was a natural consequence of this.

\section{Methodological discussion}

The benefits behind focus group design are that group processes can help the informants to explore and clarify their own views by interacting with each other. This interpersonal communication can highlight (sub) cultural values and/or group norms (Kitzinger, 1995, Morgan, 1997). This is particularly important in studies of sensitive and taboo topics (Robinson, 1999). To use pre-existing groups, homogenous in nature, as we did in this study makes the informants feel more secure and comfortable and will promote a more open communication. Informants can also provide mutual support for each other in the way that they will often express feelings that are common to their group and thereby the less reserved members of the group can break the ice for the shyer ones (Kitzinger, 1995, Morgan, 1997). The size of a focus group 
interview is normally from 4-12 informants and is coordinated by a moderator (Kitzinger, 1995, Morgan, 1997). Given the sensitive nature of the topic of this study and the high levels of involvement from the support group members the size of each focus group was limited to four women in each group. This in order to facilitate a more open sharing of views and also giving everybody the possibility to make their voice heard (Morgan, 1997, Robinson, 1999). In this study the strength is the fact that the women had identified themselves as breast cancer patients and were secure and confident as group members. The limitation according to our informants is the homogeneity in age, types of cancer treatment and social background. The translation procedure is a sensitive task, writing in another language than mother tongue. Therefore the original quotes were interpreted in a two way dialog with a very experienced language reviser. Qualitative studies like this is not aiming to generalise findings in terms of the whole population, hence the findings of this study could be transferable to a similar group of women elsewhere. There are many different reasons why women choose to join a supportive group. The educational aspects and the fact that this is a way to meet other women in the same situation are probably dominating (Söderholm Werkö, 2008).

During the analysis, the first author collaborated with the other authors and focused on not allowing pre-understanding to influence the results. The results of the study are further strengthened by the fact that the findings have been discussed during several personal dialogs with members of the support groups.

\section{CONCLUSIONS AND IMPLICATIONS}

Middle-aged women with a breast cancer diagnosis being treated with anti cancer drugs experienced their body in a wholly new and unfamiliar way. These bodily experiences can have a huge impact and accelerate their feeling of being an outsider. This feeling can successively affect their sexuality and womanhood. From a nursing perspective there appears to be a definite challenge to talk about and confirm the women's feelings and thoughts, not only about sexual dysfunction but also feelings connected to body changes, attraction and womanliness during treatment and the following rehabilitation period. It is time to open a dialog and guide the woman and her family through her cancer therapy in a more individual way than that which is often the norm today. Nurses often have the role of co-ordinator to the rest of the professional 
care team. The patients would probably benefit from help given by a physiotherapist offering relaxation and body exercise. A future challenge would be to create a collective language and epistemology relating to sexual issues. Further, co-operation between the women patients and supportive groups can also be a beneficial way of breaking the taboos and norms connected to sexuality in this context. 


\section{REFERENCES}

Addis I. B., Van Den Eeden S. K., Wassel-Fyr C. L., Vittinghoff E., Brown J. S. \& Thom D. H. (2006) Sexual Activity and Function in Middle-Aged and Older Women. OBSTETRICS \& GYNECOLOGY 107 755-764.

Andersen B. \& Cyranowski J. (1994) Women's Sexual Self-schema. Journal of Personality and Social Psychology 67, 1079-1100.

Berterö C. \& Wilmoth M. (2007) Breast Cancer Diagnosis and Its Treatment Affecting the Self. A Meta-Syntesis. Cancer Nursing 30, 194-202.

Burwell S., Case L., Kaelin C. \& Avis N. (2006) Sexual Problems in Younger Women after Breast Cancer Surgery. Journal of Clinical Oncology 24, 2815-2820.

Fenlon D., Corner J. L. \& Haviland J. (2009) Menopausal hot flushes after breast cancer. European Journal of Cancer Care 18, 140-148.

Fenlon D. R. \& Rogers A. E. (2007) The Experience of Hot Flushes after Breast Cancer. Cancer Nursing 30, 19-26.

Ganz P. A., Greendale G. A., Petersen L., Kahn B. \& Bower J. E. (2003) Breast Cancer in Younger Women: Reproductive and Late effects on Treatment. Journal of Clinical Oncology 21, 4184-4193.

Graneheim U. H. \& Lundman B. (2004) Qualitative content analysis in nursing research: concepts, procedures and measures to achieve trustworthiness. Nurse Education Today 24, 105-112.

Kaplan H. (1992) A Neglected Issue: The Sexual Side Effects of Current Treatments for Breast Cancer. Journal of Sex \& Marital Therapy 18, 3-18.

Kitzinger J. (1995) Introducing focus groups. British Medical Journal 311, 299-302.

Klaeson K. \& Berterö C. (2008) The lived experience of breast cancer and sexuality after premature menopause. International Journal of Qualitative Studies on Health and Wellbeing 3, 185-193.

Knobf M. T. (1998) Natural Menopause and Ovarian Toxicity Associated with Breast Cancer Therapy. Oncology Nursing Forum 25, 1519-1530.

Morgan D. L. (1997) Focus Groups as Qualitative Research. Sage Publications, London.

Mortimer J. E., Boucher L., Baty J., Knapp D. L., Ryan E. \& Roland J. H. (1999) Effect of Tamoxifen on Sexual Functioning in Patients With Breast Cancer. Journal of Clinical Oncology 17, 1488-1492.

Murkies A. (1996) Sex and the postmenopausal woman. Australian Family Physician 25, 509517.

Robinson N. (1999) The use of focus group methodology - with selected examples from sexual health research. Journal of Advanced Nursing 29, 905-913.

Rogers M. \& Kristjanson L. J. (2002) The Impact on Sexual Functioning of Chemotherapyinduced Menopause in Women With Breast Cancer. Cancer Nursing 25, 57-65.

Rowland J., Desmond K., Meyerowitz B., Belin T., Wyatt G. \& Ganz P. (2000) Role of Breast Reconstructive Surgery in Physical and Emotional Outcomes Among Breast Cancer Survivors. Journal of National Cancer Institute 92, 1422-1429.

Sulik G. A. (2007) On the Receiving End: Women, Caring, and Breast Cancer. Qualitative Sociology 30, 297-314.

Swedish National Institute of Public Health (1996) Sex I Sverige: Om sexualivet $i$ Sverige (In Swedish). 
Söderholm Werkö S. (2008) Achieving Patient Empowerment through active participation, increased knowledge and organisation. Elanders, Stockholm.

Who \& Sexology W. A. F. (2000) Promotion of Sexual Health Recommendations for Action. Guatemala.

Wilmoth Chamerlain M. (2001) The aftermath of breast cancer: an altered sexual self. Cancer Nursing 24, 278-286.

Young-Mccaughan S. (1996) Sexual functioning in women with breast cancer after treatment with adjuvant therapy. Cancer Nursing 19, 308-319. 